\title{
Viver e morrer com dignidade: no que diferem e no que se assemelham a sucessão do cônjuge e a do companheiro à luz da doutrina e dos pronunciamentos dos tribunais?
}

\begin{abstract}
Live and die with dignity: what are the differences and similarities in the sucession of spouce and companion in the doctrine and pronouncements of the courts?
\end{abstract}

\section{Giselda Maria Fernandes Novaes Hironaka*}

\section{Resumo}

Desde a promulgação e vigência do Código Civil de 2002, vigente para nós brasileiros, um dos mais polêmicos assuntos reiteradamente enfrentados pela doutrina e pelos tribunais é, certamente, a sucessão do cônjuge e do companheiro sobrevivo, estampada nos artigos 1.829 (combinado com o 1.832) e 1.790, respectivamente. Não poderia ter sido mais infeliz o legislador, ao registrar, em diferentes lócus as regras sobre um e outro caso, tratando desigualmente situações que já se encontravam constitucionalmente equalizadas no que diz respeito à tutela dos direitos decorrentes das relações advindas do casamento e da união estável. Este texto busca examinar criticamente essas divergências, apontando a urgente e imprescindível necessidade de reformas e/ou de exclusões legislativas que afastem as distorções inaceitáveis, alocando a sucessão do companheiro no mesmo patamar de direitos que se defere ao cônjuge, isto é, no espaço da sucessão legítima e com regras equalizadas.

Palavras-chave: Sucessão do cônjuge. Sucessão do companheiro. Equalização. Reforma legislativa.

Doutorado em Direito pela Universidade de São Paulo (1982), livre docência em Direito pela Universidade de São Paulo (2003) e titularidade em Direito Civil pela Universidade de São Paulo (2010). Professora Titular do Departamento de Direito Civil da Faculdade de Direito da Universidade de São Paulo (FDUSP). Professora Mestrado/ Doutorado em Direito na USP. Coordenadora titular da área de Direito Civil da Escola Paulista de Direito (EPD). Coordenadora titular do Programa de Pós-graduação Stricto Sensu em Direito da Faculdade Autônoma de Direito de São Paulo (FADISP). São Paulo - SP Brasil. E-mail: hironaka@uol.com.br 


\section{Abstract}

Since the enactment and duration of the Civil Code of 2002, effective for us Brazilians, one of the most controversial issues repeatedly faced by doctrine and courts is certainly the succession of the spouse and the surviving mate stamped on articles 1829 (combined with the 1832) and 1790, respectively. It could not have been more unfortunate legislator to register at different locus rules on both cases, unequally treating situations that were already constitutionally equalized, with regard to the protection of the rights arising from the resulting relationships of marriage and relationships arising from stable. This text seeks to critically examine these differences, pointing out the urgent and imperative need for reform and / or legislative exclusions that remove the unacceptable distortions, allocating the succession fellow at the same level of rights that defers to the spouse, that is, in the space of legitimate succession, and equalized rules.

Keywords: Succession of spouse. Companion succession. Equalization. Legislative reform.

\section{Introdução}

Doze anos de promulgação e onze anos de vigência. Estas são as "idades” do Código Civil brasileiro, já não tão jovem, mas que ainda carrega, no seu Livro V - Direito das Sucessões - os mesmos problemas, defeitos e carências com os quais veio ao mundo jurídico.

Há doze anos, durante o período de vacatio legis do Código, houve a oportunidade de estarmos em Brasília, durante duas semanas, a pedido da Ouvidoria Parlamentar da Câmara dos Deputados, para debatermos com os senhores deputados federais todo o Código Civil recém-promulgado, em uma varredura extensa e vertical de todos os seus livros, incluindo, por certo, este importante e desastradamente construído Livro V - Direito das Sucessões. ${ }^{1}$ Lembro-me bem de que

\footnotetext{
Nossas intervenções, àquela época, se encontram insertas num volume produzido pela própria Câmara dos Deputados (Ouvidoria Parlamentar, Procuradoria Parlamentar e Terceira Secretaria), por meio de seu Centro de Documentação e Informação - Coordenação de Publicações, em 2003, sob o nome de "Novo Código Civil - o que muda na vida do cidadão". Neste Seminário e nesta correspondente obra, o Professor Zeno Veloso e eu estivemos encarregados de explanarmos a respeito do $\mathrm{V}$ e último Livro da Parte Especial da nova Lei Civil, justamente sobre o Direito das Sucessões. Nossas considerações estão registradas nas p. 253-278.
} 
esteve presente conosco, quase todo o tempo, S. Exa. o Professor Miguel Reale, ilustríssimo presidente da comissão de juristas notáveis que havia edificado o Projeto 634-B, que deu origem, depois, à Lei $\mathrm{n}^{\circ}$ 10.406/2002, exatamente o nosso Código Civil em vigor.

Ali dissemos - Professor Zeno Veloso e eu - tudo o que prosseguimos dizendo durante toda esta dúzia de anos, por todo este país, e mesmo fora dele, incansavelmente, em terra e no mar. $^{2}$ Mas nada se modificou na Lei, e as nossas reclamações e advertências permaneceram no eco de nossas vozes, reproduzidas pela rica doutrina de nossos pares e acatadas, por vezes, pela voz corajosa deste ou daquele julgado.

De lá até esta parte, muito se disse, escreveu e julgou. Professor Zeno Veloso, o maior dos sucessionistas vivos do nosso país, muito já escreveu sobre o tema e suas palestram ecoam pelos ouvidos de todos nós, exceto pelos ouvidos moucos do legislador brasileiro.

Eu mesma escolhi, para pesquisar, escrever e defender, sob arguição de doutíssimos mestres (entre eles o Professor Fachin, o Professor Tepedino e o Professor Francisco Amaral), em minha derradeira tese acadêmica - no meu concurso para Professor Titular da Faculdade de Direito do Largo São Francisco (USP) -, tema sucessionista dos mais controvertidos, do qual gosto profundamente: concorrência sucessória do cônjuge e do companheiro. ${ }^{2}$

E tanto pesquisei e estudei exatamente para, mais uma vez, em 2010, deixar registrados os terríveis enganos praticados pelo legislador a respeito desse assunto, quando decidiu criar o novo instituto, sem o cuidado mínimo de testar matematicamente a própria regulamentação. Fiz desse reclamo inicial, em 2002, em Brasília, o centro de minha atenção científica, nesse derradeiro momento de ascensão em minha carreira

2 Recentemente estivemos a bordo de um navio, na costa brasileira, participando de um congresso que contou com a participação de muitos de nós, associados ao IBDFAM.

3 A tese de titularidade da autora resultou no livro: Morrer e suceder: passado e presente da transmissão sucessória concorrente. 2. ed. São Paulo: RT, 2013. 
acadêmica. O que vou dizer pode parecer paradoxal ou pleonástico: penso que morrerei dizendo e escrevendo sobre a sucessão mortis causa, seus meandros e suas confusões. Afeiçoei-me...

\section{Semelhanças e dessemelhanças entre a sucessão do cônjuge e a do companheiro}

Sobre as dessemelhanças entre a sucessão do cônjuge e a do companheiro, conforme solicitado pelo tema desta minha breve intervenção, não terei dificuldades em apontá-las. Sobre as semelhanças, já não poderei dizer o mesmo. O legislador ordinário, mesmo tendo a Constituição Federal à época (2002) quatorze anos de vigência, desconsiderou completamente a equalização que o legislador constitucional havia corajosamente considerado entre o casamento e a união estável, e tratou desequalizadamente as duas entidades familiares que merecem a mesma proteção do Estado.

\section{O habitat legal da sucessão do cônjuge e o habitat legal da sucessão do companheiro e a ordem da vocação hereditária de um e outro para herdar por direito próprio}

Tratou-se a sucessão do cônjuge no artigo 1.829 do Código, dispositivo legal que se encontra inscrito no Capítulo I do Título II do Livro V, denominado Da Sucessão Legítima. E tratou-se da sucessão do companheiro, de modo completamente diverso, no artigo 1.790, que se encontra, por sua vez, inscrito no Capítulo I do Título I, denominado Das Disposições Gerais... Disposições Gerais! Não posso deixar de pensar que o legislador, ao tempo da inserção das disposições relativas à sucessão do companheiro, no Projeto, preconceituosamente não quis lhe dar assento no mesmo habitat legal destinado ao cônjuge, empurrando a regulamentação para o ambiente das meras disposições gerais...

Para ambos, estabeleceu a sua colocação em uma ordem de vocação hereditária, mas a relação preferencial para o cônjuge (que o 
coloca em terceira chamada, se ausentes descendentes e ascendentes) é muito diferente da relação preferencial para o companheiro (que o colocou em quarta, e última, chamada, depois de descendentes, de ascendentes, e até mesmo depois de colaterais até o quarto grau - tioavô, por exemplo!).

Tem toda a razão Zeno Veloso quando conta e repete, indignado, a história do Nagibão, que vivia em Belém, em união estável com uma cabocla, durante muito tempo. Quando faleceu, rico, apareceu um primo, de Beirute, que o Nagibão nunca tinha visto e recebeu quase toda a fortuna, deixando a companheira praticamente à míngua, porque a lei brasileira (artigo 1.790, III, CC) colocou os colaterais à frente do companheiro na ordem da vocação hereditária, deferindo a este, concorrentemente, apenas um pequeno percentual do acervo!

As regras - bem se nota - divergem absurdamente.

$\mathrm{Na}$ sucessão do cônjuge, em terceiro lugar de vocação para herdar, ele mesmo (o cônjuge sobrevivente) é quem será chamado (art. 1.829, III) e herdará todo o acervo, sem restrição ou recorte. Apenas na sua ausência, e em quarto lugar, serão chamados a herdar todos os parentes colaterais, até o quarto grau de parentesco (art. 1.829, IV), estabelecendo-se, entre eles, certa ordem legal de preferência.

Já na sucessão do companheiro - bem se registre - apenas na última ordem de vocação hereditária, e a teor do artigo 1.790, IV, será chamado a herdar a totalidade do acervo, o companheiro do falecido, a ele sobrevivente. Antes dele (companheiro sobrevivo) - já se viu - serão chamados a herdar todos os demais parentes sucessíveis do morto, ascendentes e colaterais até o quarto grau de parentesco. ${ }^{4}$

Como se vê, é evidente a falta de sistema e de coerência - e até de justiça - existente entre esses dois dispositivos do Código Civil (art.

Como mencionado, ao descrever a história do Nagibão, poderá ocorrer a concorrência desses parentes colaterais com o companheiro sobrevivente. 
1.829 e 1.790), mormente levando-se em conta que o artigo 1.790 se encontra topicamente mal localizado no corpo legislativo, como se fosse uma infeliz inserção de última hora que não estivesse nada preocupada em obedecer à regra equalizadora da própria Constituição Federal brasileira.

Na verdade, o que o legislador pátrio criou foi um sistema díspar de vocação do cônjuge, especialmente como herdeiro concorrente, que troca as regras conforme o regime de bens do casamento que tenha sido adotado entre ele e o autor da herança. E criou outro sistema de regência da sucessão concorrente para o companheiro sobrevivo (se o autor da herança houvesse falecido sob o estado civil decorrente de união estável), totalmente diverso do sistema destinado ao cônjuge supérstite, o que tem criado vários problemas, sendo que o mais importante ou significativo deles alcança dúvidas acerca da constitucionalidade de tal diversidade de sistemas.

\section{Os pressupostos e as regras do Código para a concorrência do cônjuge ou para a concorrência do companheiro, com descendentes do falecido}

Caminhando adiante, em busca das dessemelhanças entre a sucessão do cônjuge e a do companheiro, ocorre-me, agora, anotar o sistema escolhido pelo legislador para conferir o status de herdeiro concorrente àquele, agora sobrevivo, que vivera casado com o falecido, ou que com ele vivera em união estável. Esse sistema está baseado, já se disse, no regime de bens por eles adotado e na qualificação dos descendentes com os quais concorrerão.

Assim, o primeiro pressuposto a ser vencido quando se dá a abertura de uma sucessão, visando à correta vocação dos herdeiros - tanto os de chamada própria, como os que serão concorrentemente chamados - consiste em perquirir qual era o estado civil (se casado ou companheiro), qual era o regime de bens do autor da herança e, ainda, qual a qualificação dos descendentes, relativamente àquele que com 
eles concorrerá. Nesse ponto, ao prever a concorrência tanto do cônjuge como a do companheiro, em determinadas hipóteses sucessórias e sob determinadas condições, o Código Civil atual estabeleceu regras que dependem da resposta que se dará às questões, para que, a partir de então, bem possa proceder à análise da partição da herança. (HIRONAKA, 2013, p.361-362)

Dito de outra forma, se o sobrevivente tiver sido casado com o autor da herança em regime compatível com a concorrência (regime da comunhão parcial se o falecido houver deixado bens particulares, regime da separação convencional ${ }^{5}$ e regime da comunhão final dos aquestos), então concorrerá com os descendentes do morto, e sua quota hereditária variará conforme esses descendentes sejam ou não seus descendentes também. Mas se o sobrevivente tiver vivido estavelmente com o autor da herança, já não indagará a lei acerca do regime de bens que norteou a união, apenas estabelecendo regras para a mensuração do quinhão hereditário, conforme a concorrência se dê com descendentes comuns, ou com descendentes exclusivos do morto. A dessemelhança é gritante, mais uma vez.

Assim, e como se disse, se para as pessoas casadas o direito a concorrer era limitado pelo tipo de regime de bens vigente (art. 1.829, I, CC), a restrição da espécie de bens sobre os quais deverá incidir a concorrência do companheiro sobrevivente está expressa no caput do artigo 1.790 do CC (sucessão apenas relativamente aos bens onerosamente adquiridos na vigência da união estável), irradiando seus efeitos por toda a construção legislativa estabelecida pelos seus incisos. (HIRONAKA, 2008, p.207)

\footnotetext{
Sempre é preciso lembrar e anotar que há significativo julgado do STJ, cuja relatoria coube à Ministra Nancy Andrighi, segundo a qual este regime da separação convencional também é um regime incompatível com a concorrência sucessória, pelas razões ali indicadas. Convém examinar: REsp 992.749-MS (2003/0229597-9).
} 


\section{Oacervo patrimonial sobre o qual incidirá a concorrência sucessória do cônjuge ou do companheiro: acervo de bens particulares ou acervo correspondente à antiga meação do agora autor da herança?}

Quanto ao regime da comunhão parcial de bens, determina a lei uma dualidade de tratamento para aqueles que, tendo sido casados sob esse regime de regência patrimonial, possuíssem, ou não, bens particulares. Nesse caso, então, pareceu sempre à doutrina que a lógica interpretativa se fazia pelo seguinte viés: aqueles bens que compunham o patrimônio comum do casal seriam divididos, não em razão da sucessão, mas em razão da dissolução da sociedade conjugal, produzindo, por consequência, a separação das meações que diziam respeito a cada um dos membros do casal; em contrapartida, os bens exclusivos do autor da herança - relativamente aos quais o cônjuge sobrevivente não tem direito à meação - seriam partilhados entre ele, o sobrevivo (por força da concorrência), e os descendentes do autor da herança, em razão da sucessão causa mortis.

Contudo, mais uma vez não é possível deixar de referir o julgado do STJ, também de relatoria da Ministra Nancy Andrighi, segundo o qual a concorrência do cônjuge sobrevivo, nessas condições e sob esse regime de bens, deveria recair sobre o acervo de bens correspondente à antiga meação do falecido, quer dizer, sobre a metade dos bens adquiridos na constância do casamento. Mais uma vez se registra que é necessário conferir as razões do acórdão, conforme o voto da Ministra. ${ }^{6}$

$6 \quad$ REsp 1.377.084-MG (2013/0083914-0). Em seu voto, a Ministra Nancy escreve que: "Nesse contexto, mais justo e consentâneo com aquela preocupação é permitir que o sobrevivente herde, em concorrência com os descendentes, a parte do patrimônio que ele próprio construiu com o falecido, porque é com a respectiva metade desses bens comuns que ele pode contar na falta do outro, assim na morte como no divórcio. Não lhe devem tocar, pois, os bens particulares; justamente aqueloutros que, no exercício da autonomia da vontade, os nubentes optaram - seja por não terem elegido regime diverso do legal, seja pela celebração do pacto antenupcial por manter incomunicáveis, excluindo-os expressamente da comunhão, como preveem os arts. 1.659 e 1.661 do CC/02 para o regime da comunhão parcial de bens". 


\section{A garantia de reserva da quarta parte a favor do cônjuge concorrente. Essa garantia de reserva não se produz a favor do companheiro concorrente}

Se não bastasse, outra dessemelhança impressionante diz respeito à regra contida no artigo 1.832 do Código Civil, que proporciona garantia de reserva obrigatória de quarta parte do acervo patrimonial sobre o qual incidir a concorrência, exatamente a favor do cônjuge concorrente, se esta se der com descendentes do falecido que sejam também seus descendentes. Pois bem, essa mesma regra não se reproduz a favor do companheiro que concorre com herdeiros descendentes do falecido e dos quais ele, o sobrevivo, seja também ascendente.

Dito de outro modo, a determinação legal contida no inciso I do artigo 1.790 diz apenas que, na concorrência do companheiro sobrevivo com os filhos comuns (havidos entre ele mesmo e o falecido, agora autor da herança), o herdeiro concorrente amealhará um quinhão igual ao que for atribuído a cada um desses filhos. Não há uma palavra sequer mencionando qualquer perspectiva de se resguardar, minimamente, ao companheiro concorrente, uma quarta parte do acervo, como acontece em relação ao cônjuge sobrevivo concorrente, quando este disputa com os herdeiros descendentes do falecido e que sejam, também, seus descendentes.

E assim, como se vê, prosseguem as dessemelhanças entre a sucessão de um e outro, cônjuge e companheiro, no sistema sucessório brasileiro. Infelizmente.

\section{Sobre a chamada culpa mortuária, examinada à luz da sucessão do cônjuge e também à luz da sucessão do companheiro}

Nesse passo, examinar-se-á a regra contida no artigo 1.830 do Código Civil, segundo a qual

somente é reconhecido direito sucessório ao cônjuge sobrevivente se, ao tempo da morte do outro, não estavam 
separados judicialmente, nem separados de fato há mais de dois anos, salvo prova, nesse caso, de que essa convivência se tornara impossivel sem culpa do sobrevivente. (Grifouse).

Trata-se da chamada culpa mortuária, como bem a designou Zeno Veloso. Mais um absurdo rançoso e preconceituoso do legislador brasileiro, em matéria sucessória, no Código Civil que ora vige.

Até 1977, com a impossibilidade da dissolução do vínculo matrimonial por divórcio, também não se excluía o separado de fato da sucessão do cônjuge falecido. Mas isso não é mais possível acontecer atualmente, em razão da verificação de certo lapso temporal de separação factual (dois anos). Até aqui, poderíamos considerar que houve atualização do Código condizente com o avanço decorrente da Lei do Divórcio de 1977. Mas o Código não parou aí; disse mais, ressalvando: prescreveu que prosseguiria existindo direito sucessório a favor do cônjuge separado há mais de dois anos se restasse provado que a convivência se tornou impossível sem culpa do sobrevivente. Quer dizer, foi apenas por culpa do morto que se deu a ruptura da vida conjugal...

Não há como deixar de criticar essa infeliz ressalva do legislador à possibilidade de atribuição de culpa ao falecido, com a intenção de livrar, dessa mesma culpa, o cônjuge sobrevivo e separado de fato há mais de dois anos, para que pudesse, então herdar, segundo a regra do artigo 1.830 do Código Civil. Trata-se de inserção totalmente descabida, especialmente neste tempo de pós-modernidade, quando a visão que se tem de família é algo tão distinto do que foi no passado, agora muito mais baseado no afeto do que na perquirição de culpados ${ }^{7}$.

\footnotetext{
AEmenda Constitucional n. 66/2010 trouxe importante avanço para o nosso sistema constitucional, pela interpretação de que a separação judicial não mais existe, com a ressalva de que sempre será possível a separação de fato. A discussão da culpa não é mais requisito para a dissolução do casamento, e o divórcio pode ser pedido diretamente, sem passar pela etapa da separação e sem necessidade de comprovar a insuportabilidade da vida em comum, com destaque para a imputação de culpa ao outro cônjuge.
} 
Felizmente, os tribunais têm mostrado visão diferente da descrita, demonstrando lucidez e coerência, por exemplo, o Tribunal de Justiça de São Paulo, que, em sede de apelação, marcou sua posição declarando: primeiro, que o ônus da prova é dos terceiros interessados, isto é, daqueles que alegam, para exclusão do cônjuge que herdaria (art. 1.829, III, CC), que a separação de fato para além de dois anos decorrera de culpa exclusiva do sobrevivo; segundo, que essa prova restou conflitante e inconclusiva, e não demonstrou que a apelante tivesse sido a culpada da separação de fato do casal; e que, terceiro, os apelados não demonstraram o fato constitutivo de seu direito. (SÃO PAULO. TJSP, $1^{\text {a }}$ Câmara de Direito Privado, AP 543.700.4/0-00, São José do Rio Preto, rel. Des. Paulo Eduardo Razuk, j. 03.02.2009). mesmo Tribunal de Justiça, em sede de agravo de instrumento, declarou que a possibilidade de se produzir tal prova,

além de se mostrar contrária à jurisprudência dominante no Brasil, no sentido de que a separação fática rompe o regime de bens, não parece razoável, pois [impossível] imaginar a produção de prova de culpa, de pessoa falecida, pela ruptura da vida em comum, sem que possa, ela própria defender [...]. (SÃO PAULO. TJSP. Agravo de Instrumento 516.7814/5-00, Franca, rel. Des. Ribeiro da Silva, j. 28.02.2008).

\section{Conclusão}

O próprio histórico do artigo 1.790 CC, já induz ao entendimento de que ele carrega consigo inúmeros problemas, eis que só foi inserido no texto do Projeto de Código Civil por força da Emenda $n^{\circ} 358$, apresentada pelo Senador Nelson Carneiro. Antes dele, nada constava a respeito da sucessão do companheiro, e a escolha do habitat legislativo para a sua inserção foi extremamente desastrosa, uma vez que não foi (este sistema sucessório dos que viveram sob união estável) acolhido pelo dispositivo que abrigou a ordem de vocação hereditária (o art. 1.829 do (C), mas restou instalado, como já se anotou neste estudo, fora do Título destinado à Sucessão Legítima, no Título destinado à Sucessão em Geral, no Capítulo das Disposições Gerais. 
Pois bem, o artigo 1.790 é de feição extremamente retrógada e preconceituosa, e a vigorosa maioria dos pensadores, juristas e aplicadores do direito tem registrado com todas as letras que o dispositivo é inconstitucional, exatamente porque trata desigualmente situações familiares que foram equalizadas pela ordem constitucional, como é o caso das entidades familiares oriundas do casamento e da união estável.

Os julgados acerca do assunto ainda têm oscilado muito, ora pugnando por uma linha hermenêutica, ora por outra. É muito importante, segundo o meu sentir, o registro jurisprudencial que decide pela inconstitucionalidade do dispositivo, mas o futuro não se apresenta claro. Não há, por enquanto, nem o anúncio a respeito de um julgamento definitivo que pugnasse pela ausência de constitucionalidade, nem a previsão de uma saudável e tão esperada reforma legislativa.

O tratamento dado pelo legislador, portanto, à sucessão do companheiro sobrevivo, é inconstitucionalmente distinto daquele outro, que foi dado ao cônjuge, pelo artigo 1.829 do Código Civil. Lamentavelmente. Conforme a crítica de Rolf Madaleno (2004, p.113), parece mesmo que

mais uma vez resta discriminada a relação afetiva oriunda da união estável que perde sensível espaço no campo dos direitos que já haviam sido conquistados após o advento da Carta Política de 1988, em nada sendo modificada a atual redação do novo Código Civil e será tarefa pertinaz da jurisprudência corrigir estas flagrantes distorções deixadas pelo legislador responsável pela nova codificação civil.

O autor escreveu essas palavras em 2004, quando o Código Civil tinha apenas um ano de vigência, e pareceu que elas eram premonitórias, pois, até hoje, mais de dez anos depois, a jurisprudência ainda se encontra embaraçada e emaranhada no que diz respeito a esse assunto. O sentimento derivado da constatação de que se "andou para trás" acompanha fortíssima parcela da doutrina nacional, deixando ecoar o pensamento de Zeno Veloso (2005, p.242): "O art. 1.790 merece 
censura e crítica severa porque é deficiente e falho, em substância. Significa um retrocesso evidente, representa verdadeiro equívoco".

Por todas as letras e críticas, parece ser muito clara a urgente necessidade de exclusão ou reforma que merece o Código Civil, na regulamentação dos direitos sucessórios do companheiro, para que essa distorção apontada seja afastada e para que a realocação das disposições a este tema relativas encontrem seu lugar perfeito e adequado, que é exatamente o locus legislativo da sucessão legítima, espaço especialmente deferido à ordem da vocação hereditária de parentes do falecido (seus descendentes, seus ascendentes e seus colaterais) e de seu cônjuge sobrevivo. Nesse espaço, deverá estar também a sucessão do companheiro sobrevivente.É como ansiosamente tenho pensado ao longo desee período de mais de uma década de vigência do Código Civil de 2002.

\section{Referências}

HIRONAKA, Giselda Maria Fernandes Novaes. Morrer e suceder: passado e presente da transmissão sucessória concorrente. 2. ed. rev. São Paulo: RT, 2013.

. Da ordem de vocação hereditária nos direitos brasileiro e italiano. In: AZEVEDO, Antônio Junqueira de Azevedo (Coord.). Princípios do novo Código Civil brasileiro e outros temas homenagem a Tulio Ascarelli. São Paulo: Quartier Latin, 2008. p. 191233.

MADALENO, Rolf. Direito de família em pauta. Porto Alegre: Livraria do Advogado, 2004.

VELOSO, Zeno. Do direito sucessório dos companheiros. In: DIAS, Maria Berenice; PEREIRA, Rodrigo da Cunha (Coord.). Direito de família e o novo Código Civil. 4. ed. rev. e atual. Belo Horizonte: Del Rey, 2005. p. 243-286.

Recebido em: 14/05/2015

Aprovado em: 27/12/2015 